\title{
A developed, eco-friendly, and flexible thermoplastic elastomeric foam from SEBS for footwear application
}

\author{
Z. X. Zhang ${ }^{1}$, X. R. Dai ${ }^{1}$, L. Zou', S. B. Wen ${ }^{1}$, T. K. Sinha ${ }^{2}$, H. Li ${ }^{2 *}$ \\ ${ }^{1}$ Key Laboratory of Rubber-Plastics, Ministry of Education/Shandong Provincial Key Laboratory of Rubber-Plastics, \\ Qingdao University of Science and Technology 266042 Qingdao, China \\ ${ }^{2}$ Department of Materials Engineering and Convergence Technology, Gyeongsang National University, 52828 Jinju, \\ South Korea
}

Received 26 March 2019; accepted in revised form 4 June 2019

\begin{abstract}
Developing eco-friendly, flexible thermoplastic elastomeric foams based on poly(styrene-(ethylene-co-butylene)styrene) (SEBS) is a challenging task because of its poor melt strength. A promising approach to overcome this challenge is the use of synergistic technologies, such as combination of irradiation, supercritical fluid foaming, and steam-chest molding technologies. Herein, foamed beads were produced from pre-crosslinked SEBS beads using supercritical nitrogen as blowing agent, followed by subsequently efficient steam-chest molding to obtain midsole part. The crosslinking was accomplished under the assistance of electron beam. The rheology properties and foaming behavior reveals that the viscosity and modulus of the matrix increase with the increase of crosslinking resulting from increasing the irradiation dose (ID). With increasing the $I D$, successful foaming with larger expansion and improved cell morphology was achieved. SEBS bead foams were successfully obtained from $65 \mathrm{kGy}$-derived pre-crosslinked beads through steam-chest molding which showed a specific gravity of $0.252 \mathrm{~g} \cdot \mathrm{cm}^{-3}$ and comparable/superior mechanical properties to/than that of commercial thermoplastic polyurethane (TPU) or ethylene-vinyl acetate copolymer (EVA) foams. Especially, the higher elasticity and resilience of SEBS foams meet well the desirable properties for footwear application which supports SEBS to be an alternative for TPU or EVA.
\end{abstract}

Keywords: industrial applications, irradiation, SEBS, bead foaming, flexible foam

\section{Introduction}

In search of new materials to develop comfortable shoe sole, nowadays the researchers have resorted to the thermoplastic elastomers (TPEs) usually used as cushioning materials for its easy processability and adorable physical properties that can meet both the comfort as well as other functional requirements (i.e. fashion, ultralight, aging, etc.). TPEs are a class of copolymers or physical mixes of polymers and have the morphology of non-miscible blends of elastomer and thermoplastic matrix simultaneously. Low or room temperature elastomeric behavior and high temperature processablitiy makes TPE as a suitable material for developing lightweight and recyclable microcellular foams [1]. Most of the commercial TPE foams for footwear application are developed either from thermoplastic polyurethane (TPU) or ethylenevinyl acetate (EVA) copolymer in which the soft matrix provides sufficient free space for gas absorption whereas the rigid matrix prevents the gas diffusion during foaming process [2-6]. Styrene-(ethylene-cobutylene)-styrene polymers (SEBS) derived from the hydrogenation of styrene-butadiene-styrene (SES) polymers is a typical TPE which shows a better weather resistance, lower compression set, lower density, etc., can be a potential alternative of TPU or EVA [7, 8]. SEBS consists of a soft midblock of ethylene-butylene (E-co-B) and hard end-blocks of 
polystyrene (PS) which correspond to the rubber and resinous thermoplastic domains respectively [9]. SEBS with their wide varieties of elasticity and hardness (as obtained by varying the ratio of $\mathrm{E}-\mathrm{co}$-B and PS) has been widely used in cable sheath, melt adhesive, elastic films, adhesives, plastic modifications, packaging, etc. [10-12].

Because of environment-friendliness and adjustable solvent property, supercritical fluids such as $\mathrm{CO}_{2}$ and $\mathrm{N}_{2}$ have been widely used as physical blowing agents for the production of polymer foams with a substantial improvement over the conventional foam manufacturing techniques $[13,14]$. Because of the slower diffusion rate, supercritical $\mathrm{N}_{2}\left(\mathrm{SC} \mathrm{N}_{2}\right)$ is preferable than the supercritical $\mathrm{CO}_{2}\left(\mathrm{SC} \mathrm{CO}_{2}\right)$ to obtain elastomeric foams with improved cell morphology [15]. Although a number of microcellular foams have been produced from TPE successfully, the limited expansion level (i.e. a high appearance density) and difficulty to obtain the desired cell morphology limit its applications. Actually, the expansion of TPE-based foams highly relies on the expansion of the gaseous phase dispersed within the polymer melt. During expansion of gas, the bubbles are stabilized under vitrification or crystallization of the polymer. Consequently, the rheological properties (i.e. viscosity and modulus) play a vital role to finalize the size and morphology of the cells [16-18]. Regardless the changes of the processing conditions (i.e. machine, time, temperature, pressure, etc.), the delayed vitrification (or crystallization) and large extensional deformation of the cell-wall may result in the impingement of neighboring cells followed by cell-wall rupture and cell coalescence. Multiple coalescence phenomena may eventually cause the collapse of the whole foamed structure, resulting in foaming failure [19]. To prevent this failure, blending or the crosslinking are considered as the most common and easy technique [20,21]. Blending can improve the rheological and thermal properties, and results the foam with improved cell morphology and dimensional stability. The added polymer crystallites act as the rigid fillers to enhance the heterogeneous nucleating sites and hinder the diffusion of the impregnated gas from the polymer matrix [22]. This method has been successfully applied to prepare a number of foams from polymer blends such as TPU/PLA [23], TPU/PMMA [24], EVA/PE [25], PMMA/PS [26], TPU/glycerol [27], etc. The shrinkage, caused by the recovery of polymer chains after expansion, is a critical issue for foaming failure during processing of elastomer foams. The crosslinking is required to enhance rigidity and viscosity of the polymer chains and consequently the foam shows better dimensional stability [28-31]. Normally, the polymer matrix can be crosslinked through the free radical reaction mechanism either by chemical reagents or irradiation with high energy electron beam (EB). The latter is preferably advantageous because a chemical residue free, controlled crosslinking can be achieved by controlling the applied irradiation dose (ID) [32]. There are plenty of articles in the literature regarding crosslinked TPE foams from polymer or polymer blend [15, 33-37], such as EVA, PU/EVA blend, PVC/TPU blend, NR/EVA blend, etc. During the processing of polymeric foams, irradiation crosslinking can broaden the temperature window for the SCF foaming, and improve cell morphology of the foams with high volume expansion ratio [38-40]. Taking these advantages into account, the combination of SCF foaming and irradiation can be applied for continuous manufacturing of TPE foams.

Recently, polymer bead foaming technology has received an immense attention due to its ability to manufacture low-density foamed components with complex geometrical structure [41,42]. The parts are manufactured from expanded polymeric beads which are welded with each other into three-dimensionally shaped products. Firstly, the foamed beads are produced from the creation of expandable beads or the production of already expanded beads. During parts manufacturing, the foamed beads are welded together in a steam-chest machine. The surface of the beads are molten or softened using high pressure steam which leads to an inter-diffusion among the polymer chains of different beads, and resulting in cohesion of the beads [43]. This technology is applied for various polymers, such as expanded polypropylene (EPP), expanded polystyrene (EPS), expanded PLA, expanded TPU [44-47].

There are very limited studies with SEBS, very few recent activities primarily reported with SEBS/PS and SEBS/PP foams [20, 48, 49]. Instead of the SEBS composites, herein, the pristine SEBS was saturated and expanded in $\mathrm{SC} \mathrm{N}_{2}$. To improve the cell morphology and anti-shrinkage properties, SEBS beads were pre-crosslinked under high energy irradiation [38]. The irradiation provides increased melt viscosity and strength to the SEBS. Also, the effect of $I D$ on foaming behavior is investigated. Moreover, the 
properties of these foams were compared with commercial EVA or TPU-based foams to evaluate their practical applicability in the footwear industry. Also, SEBS bead foam has broadened the polymers types suitable for bead foaming and thereby widened the area of possible applications.

\section{Experimental}

\subsection{Materials}

The SEBS copolymers (Tuftec ${ }^{\mathrm{TM}}$ P1083) with styrene/ethylene-butylene ratio of 20/80, density of $0.89 \mathrm{~g} \cdot \mathrm{cm}^{-3}$, a hardness of $56^{\circ}$ Shore A, and melt flow index of $3.0 \mathrm{~g} \cdot 10 \mathrm{~min}^{-1}$ (at $190^{\circ} \mathrm{C}, 2.16 \mathrm{~kg}$ ) was supplied by Asahi Kasei Corporation. $\mathrm{N}_{2}$ with a purity of $99.5 \%$ was used.

\subsection{Processing}

As shown in Figure 1, the fabrication of SEBS-based shoe sole includes the three steps: (1) crosslinking of SEBS by EB irradiation, (2) foamed bead manufacturing from EB-irradiated SEBS (I-SEBS), and (3) steam-chest molding of expanded SEBS beads (E-SEBS). Firstly, SEBS was exposed to EB irradiation at various doses $(0,20,35,50,65 \mathrm{kGy})$. Secondly, the foaming process was carried out following the temperature-induced batch foaming technology. The saturation of I-SEBS beads with $\mathrm{SC}_{2}$ was carried out at $80^{\circ} \mathrm{C}, 18 \mathrm{MPa}$ for $2 \mathrm{~h}$ with a lab-scale autoclave system. The $\mathrm{N}_{2}$-loaded SEBS beads were taken out of the autoclave without an immediate expansion. By immersing the saturated beads in the oil at an applied temperature of $150^{\circ} \mathrm{C}$ for $5 \mathrm{~min}$, the beads were expanded. Subsequently the expanded beads were stabilized at room temperature $\left(23 \pm 2{ }^{\circ} \mathrm{C}\right)$ for $72 \mathrm{~h}$. Finally, lab-scale steam chest molding equipment (manufactured by DABO Precision (DPM0404VS)) was used for molding the SEBS bead foams. The procedure follows filling of beads with SC $\mathrm{N}_{2}$, steam heating followed by surface bonding among beads, depressurization of the mold for the steam removal, water cooling for product stabilization, and ejecting of the molded product, which has been described in detail by Ge et al. [47]. The specific parameter set used in this work is that a steam with a pressure of 3.9 bar and a temperature of $142.7^{\circ} \mathrm{C}$ was applied to heat the fully filled beads for $55 \mathrm{~s}$.

\subsection{Characterization}

The crosslinking density was determined by a magnetic resonance crosslinking density spectrometer (VTMR20-010V-T, Shanghai Niumag Electronic Technology Co., Ltd., China) with a ${ }^{1} \mathrm{H}$ frequency of $21.31 \mathrm{~Hz}$ and the measurement temperature of $90^{\circ} \mathrm{C}$. The cross-linking densities were calculated with the cross-linking density XLD mode [50, 51]. Rheological properties were measured using a Rheometer (ARES G2, Rheometrics, Inc., Piscataway, NJ, USA) equipped with parallel plates with $25 \mathrm{~mm}$ diameter and $1 \mathrm{~mm}$ gap to detect the change of storage modulus $\left(G^{\prime}\right)$, loss modulus $\left(G^{\prime \prime}\right)$, complex $\operatorname{viscosity}\left(\eta^{*}\right)$, and loss angle $(\tan \delta)$ with the sweeping frequency from 0.1 to $100 \mathrm{rad} \cdot \mathrm{s}^{-1}$ at $110^{\circ} \mathrm{C}$ in the nitrogen atmosphere. Density of the foams was measured following the ASTM D792 using an electronic density meter. The cross-sectional morphology of the foam was observed using a Philips XL 30S scanning electron microscope (SEM) and average cell size was investigated using the ImageJ software from the SEM images. Cell density was calculated following the method described in our previous article [15]. The tensile, tear, and uniaxial compression test were performed using a universal tester (Gotech, Taiwan) at an extension speed of $500 \mathrm{~mm} \cdot \mathrm{min}^{-1}$ and a constant compression rate of $10 \mathrm{~mm} \cdot \mathrm{min}^{-1}$ for $50 \%$

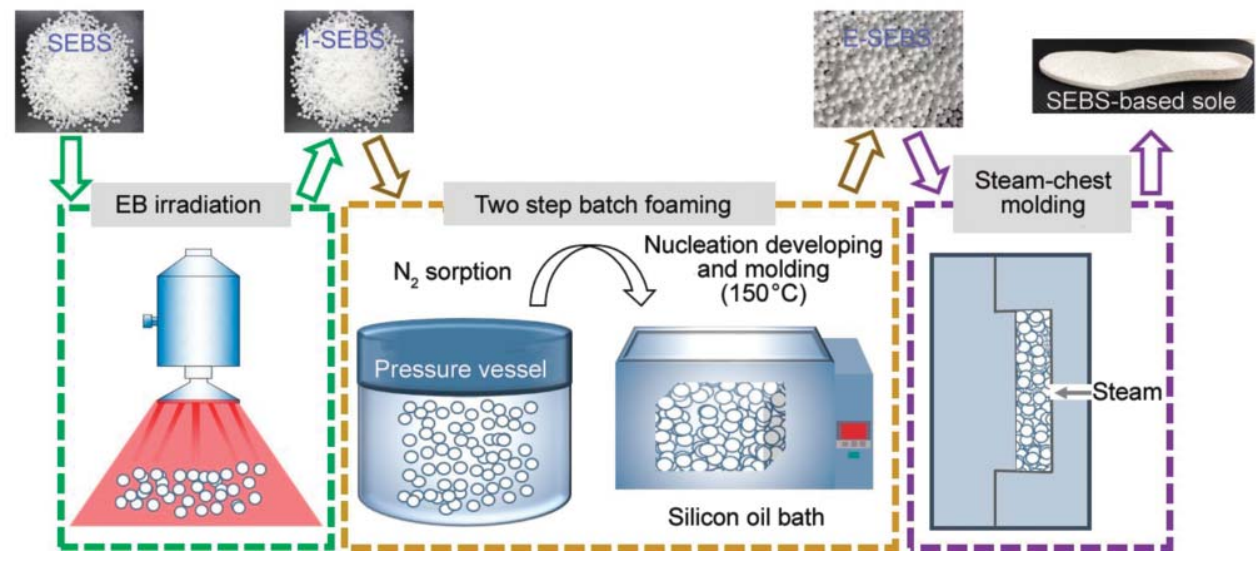

Figure 1. Schematic of fabrication process for E-SEBS beads and SEBS-based shoe sole. 
compression strain respectively. The samples were placed at a strain of $50 \%$ for $22 \mathrm{~h}$ and compression set was recorded at $24 \mathrm{~h}$ after stress release. Those tests were performed under $23 \pm 2{ }^{\circ} \mathrm{C}$ room temperature and $50 \pm 5 \%$ ambient relative humidity following the ASTM D 3575. The hardness was investigated using an AskerC Durometer following the ASTM D2240, and the resilience elasticity was measured according to the ASTM 3574 using a Zwich 3107 ball rebound tester.

\section{Results and discussion}

\subsection{Irradiation crosslinking of SEBS}

Similar to the UV radiation, high energy EB irradiation also can induce the formation of crosslinked network structure through the free-radical mechanism $[52,53]$. Here, the crosslinking can be controlled by controlling the dose of EB which is advantageous over the chemical crosslinking method. Photocrosslinking of SEBS by EB irradiation is shown in Figure 2. Corresponding $I D$ dependent the degree of crosslinking i.e., crosslink density of SEBS was direct determined by magnetic resonance crosslinking density spectroscopy and shown in Figure 3.

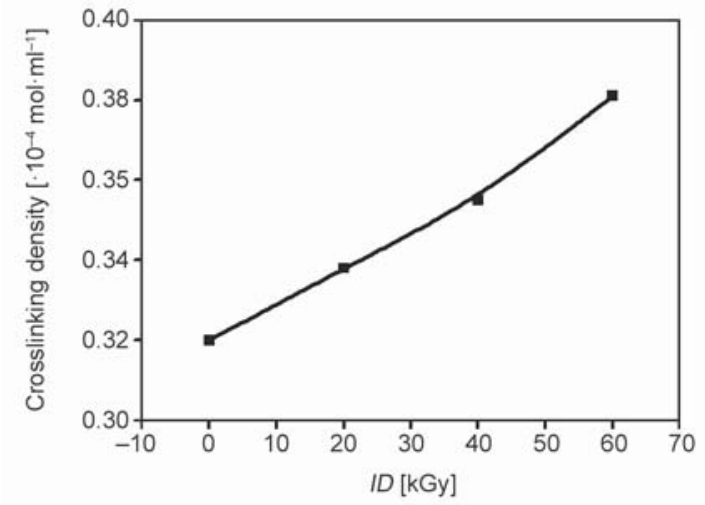

Figure 3. Crosslinking density of SEBS beads with increasing $I D$.

As exposed to the EB irradiation, the generation of free radicals on the vinyl group of butene and styrene segments and simultaneous formation of $\mathrm{C}-\mathrm{C}$ bond through inter/intra molecular crosslinking produced the three-dimensional networks structure of crosslinked SEBS. When the SEBS bead was exposed to the higher $I D$, more radicals were formed to initiate the more free radical coupling, and a crosslinked SEBS product with a higher crosslinking density was obtained. This is verified in Figure 3 that the crosslinking density of I-SEBS increased with increasing

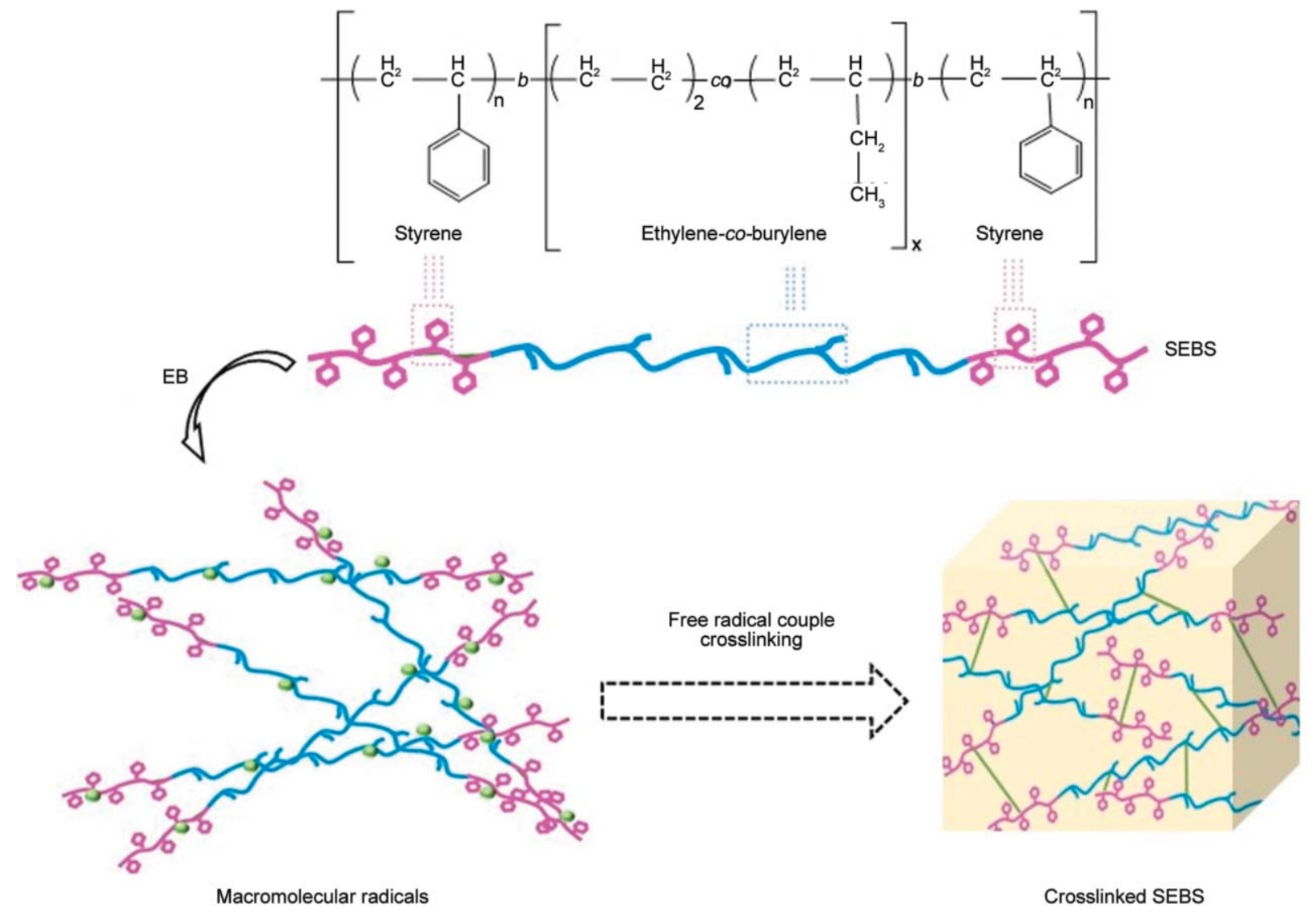

Figure 2. Schematic route indicating introduction of crosslinking in SEBS matrix with EB irradiation. The ethylene-co-butylene, styrene, and crosslinking point are indicated by blue, purple, and green respectively. 
ID from 0 to $60 \mathrm{kGy}$. Now, the mobility of polymer chain will be restricted more with increasing the crosslink density. Thus, the ID can affect the matrix rheology (i.e. viscosity and modulus), and contributes a vital role on cell nucleation and growth during foam processing.

To study the effect of EB irradiation on the rheological property, the dynamic viscoelastic behavior (i.e., $G^{\prime}, G^{\prime \prime}, \eta^{*}, \tan \delta$ ) of the I-SEBS samples were carried out (Figure 4 and Figure 5). $G^{\prime}$ and $G^{\prime \prime}$ provide information of elastic response and viscous response respectively. The viscoelastic character of the material is characterized by $\delta$, which is $90^{\circ}$ for viscous liquid and $0^{\circ}$ for ideal elastic solid. Being a linear triblock copolymer, SEBS exhibits the pseudoplastic fluid (shear thinning) behavior and has an elastic response $\left(\tan \delta<1\right.$, or $\left.G^{\prime}>G^{\prime \prime}\right)$ at very low frequency [54]. As per the above discussed, at higher $I D$, formation of enhanced network structure of SEBS due to the higher crosslink density was favored, which hindered the movement of molecular chain and enhanced the relaxation [55]. As a result, it can be noticed from Figure 4 and Figure 5 that the $G^{\prime}$ and $\eta^{*}$ simultaneously increased with increasing the applied $I D$. A predominantly elastic response was shown in I-SEBS along with the variation of frequency. A larger dosage of irradiation owning to the higher energy significantly initiate more crosslinking point which further increases the viscoelasticity of SEBS phase. The enhanced viscoelasticity lowers the damping property, which is in accordance with the decreasing trend of $\tan \delta$ with increasing the $I D$.

\subsection{Foaming behavior of the I-SEBS bead}

The $\mathrm{N}_{2}$-dived foaming process involves the formation of SEBS $/ \mathrm{N}_{2}$ solution through sorption or dissolution of $\mathrm{N}_{2}$ in the matrix under a certain pressure

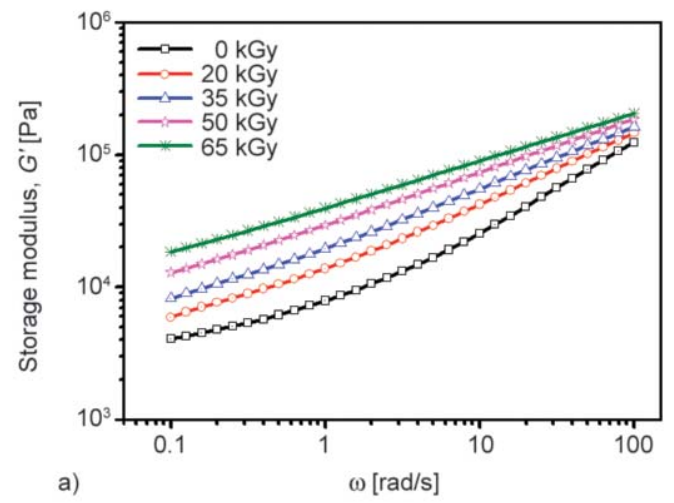

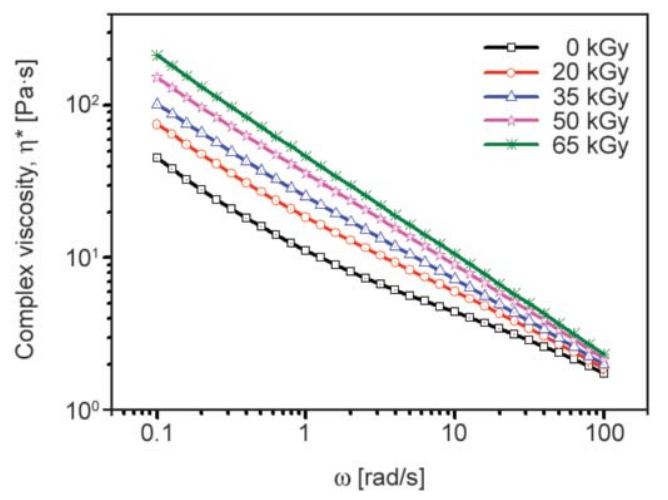

Figure 5. Frequency dependence of the complex viscosity, $\eta^{*}$ at different $I D$ s for I-SEBS.

followed by bubble nucleation and growth upon an increase of temperature. The bubble growth ends upon vitrification of SEBS and the foam structure is stabilized. The outcomes (i.e. pore size and morphology), are intimately connected to the solubility and diffusivity of $\mathrm{N}_{2}$, the interfacial tension between the polymer matrix and $\mathrm{N}_{2}$, rheological properties of the polymer, transition temperatures of the polymer and its associated vitrification processes. In this study, the rheology properties of the system were controlled by controlling the dose of irradiation. The enhanced viscoelasticity (i.e. increased viscosity and modulus) can hasten the vitrification and hinder extensional deformation of the cell-wall to prevent cellwall rupture and cell coalescence.

SEM micrographs of E-SEBS foams obtained at various $I D$ are shown in Figure 6 and respective density, average cell size and cell density are depicted in Figure 7 , respectively. It has been reported that without crosslinking foam with maximum unfoamed regions are formed, while at a certain limit of crosslinking the foam with more cell structure and very less unfoamed regions are obtained. Beyond the limit, with higher crosslinking again the more unfoamed regions are

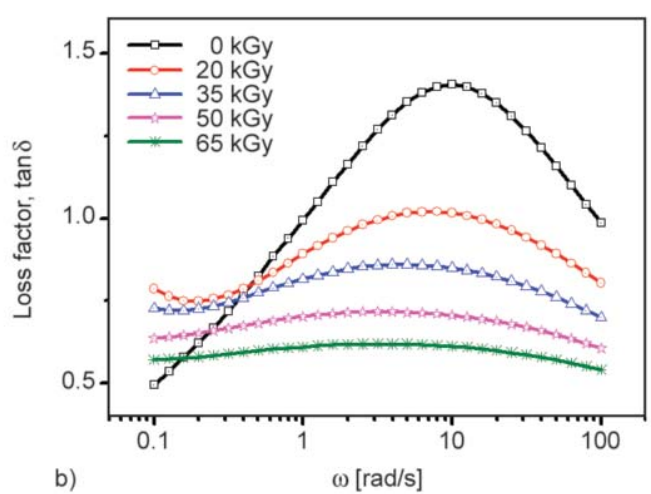

Figure 4. The magnitude of (a) storage modulus, $G^{\prime}$ and (b) loss factor, $\tan \delta$ of the dense suspensions as a function of frequency, $\omega$, at various $I D$ s for I-SEBS. 


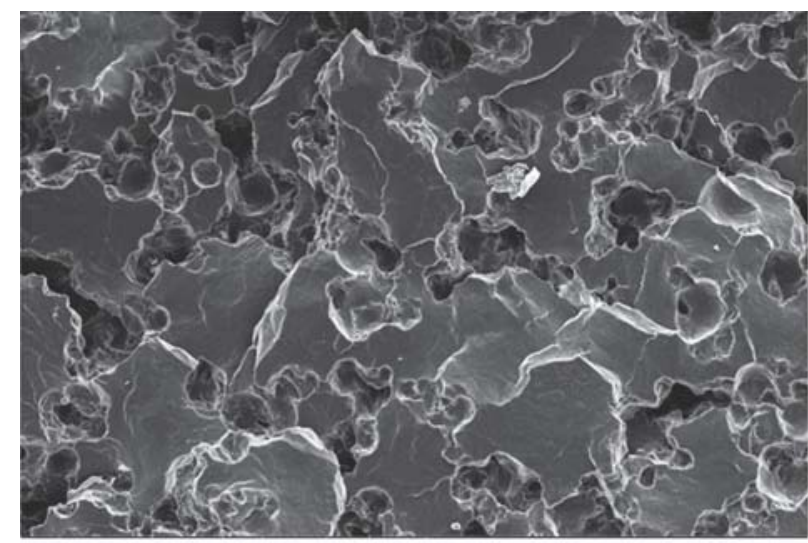

a)

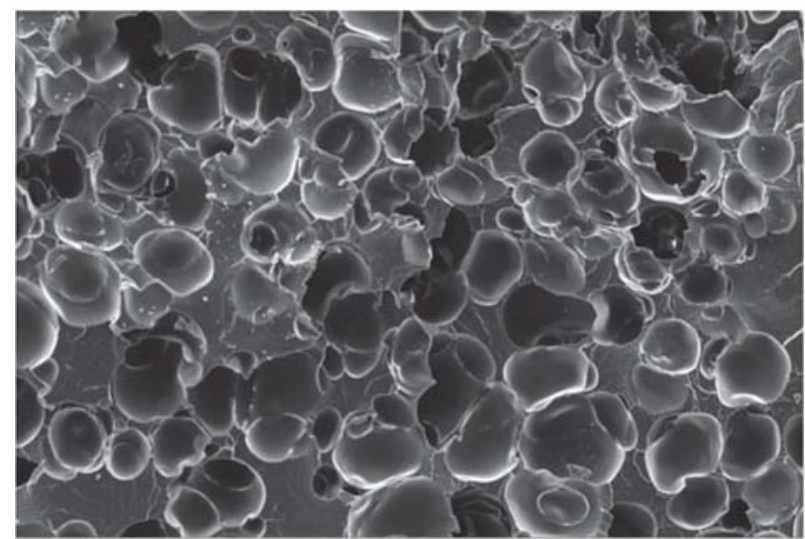

c)

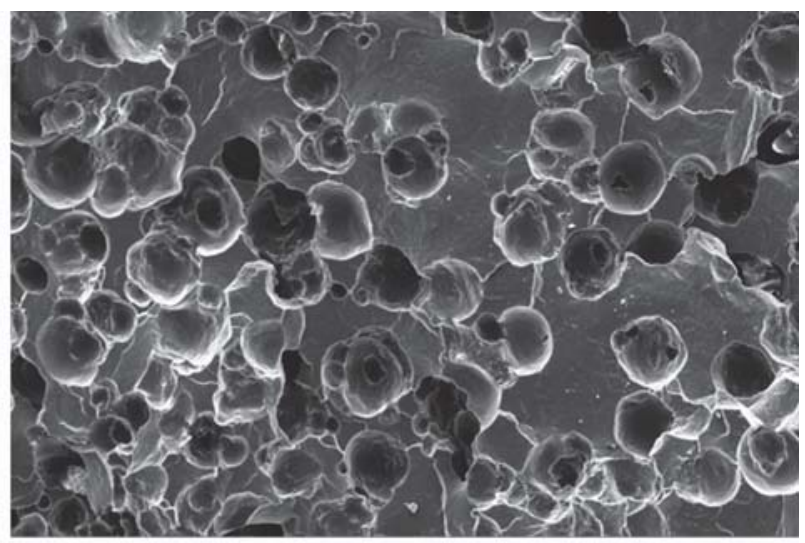

b)

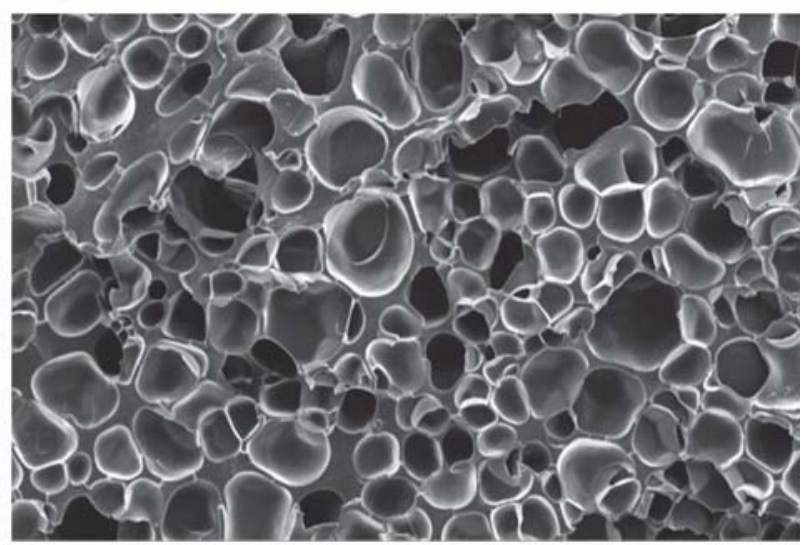

d)

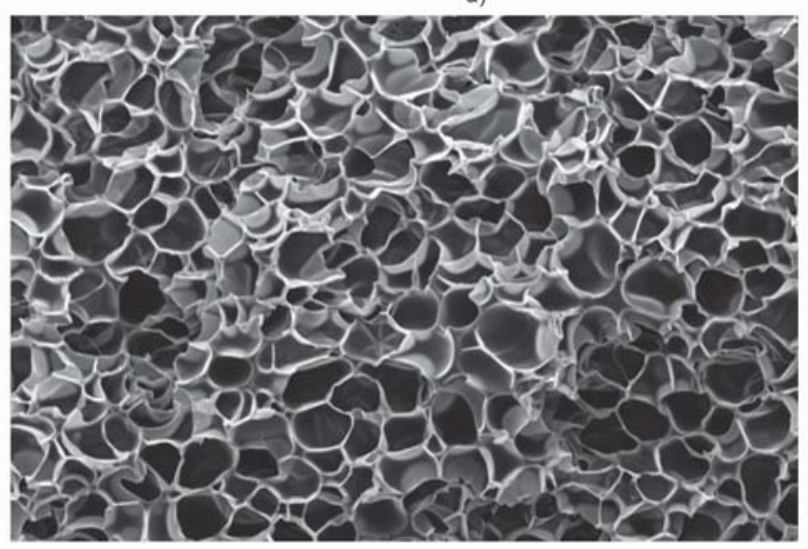

e)

Figure 6. SEM micrographs of the crosslinked SEBS foams prepared under different $I D$ : (a) $0 \mathrm{kGy}$, (b) $20 \mathrm{kGy}$, (c) $35 \mathrm{kGy}$, (d) $50 \mathrm{kGy}$, (e) $65 \mathrm{kGy}$.

predominant due to less gas sorption capability of the highly crosslinked rigid polymer matrix [56]. So there is a certain limit of crosslinking to obtain better quality foam with a well-defined cell density and cell size. Basically, crosslinking provides the well-defined spaces within the interconnected regions (like honeycomb structure) to absorb and store the super critical fluid (i.e., $\mathrm{N}_{2}$ ) which upon desorption forms the cell. With increasing the crosslinking, the number of spaces increases and foam with higher cell density is obtained. For a particular polymer, as the reacting cites are fixed, the spaces formed due to crosslinking are specified. So, the cell size changes slightly, even with increasing the crosslink density. It is noteworthy to mention here that there is a direct relation of rheology with the crosslink density. Therefore, it can be said that there will be a certain rheology (i.e., modulus and viscosity), at which the foam of better quality can be obtained. Or, in other words, it can be said that rheology is a key parameter to control the foam quality.

In our present investigation, it has been observed that under 0 to $35 \mathrm{kGy}$ irradiation, foams of high appearance density with some interconnected regions (i.e., 


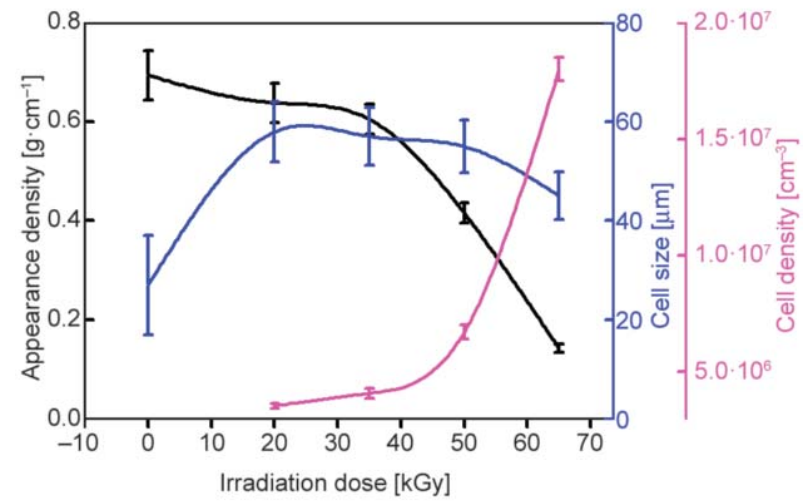

Figure 7. The variation of appearance density, average cell size, and cell density of crosslinked SEBS foams with varying the $I D$.

unfoamed regions) were obtained due to low viscosity and modulus slightly crosslinked irradiated SEBS matrix. The weak strength of non-crosslinked or slightly crosslinked SEBS and its delayed verification was impossible to prevent the coarsening densification of the foam due to the cell coalescence, and as a result the cell structure collapses. Accordingly, within the irradiation level, the interconnected regions are observed in the SEM images. These foams have the density larger than $0.6 \mathrm{~g} \cdot \mathrm{cm}^{-3}$. Once the $I D$ increased, due to the enhanced crosslinking and vitrification speeded, the $\mathrm{N}_{2}$ was effectively hindered to escape from the matrix and permanently expanded for longer period of time. As a result, when $65 \mathrm{kGy}$ was applied, no interconnected regions were found and a lightweight foam of uniformly distributed closed-cell structure with an average cell size of $50.2 \mu \mathrm{m}$ and an appearance density of $0.1 \mathrm{~g} \cdot \mathrm{cm}^{-3}$ was obtained.

\subsection{Performances of the I-SEBS bead foams after steam-chest molding}

To meet the basic requirement of lightweight in footwear application, the $65 \mathrm{kGy}$-derived I-SEBS foamed beads were used for steam chest molding

and inter-bead sintering verification. Figure 8 shows the digital photographs and SEM micrographs of molded foams obtained at a molding pressure of 3.9 bar. For the production of the parts (as shown in Figure 8 and the sintered interface highlighted with a red rectangle), the foamed beads are welded together in the steam-chest molding machine. Under high pressure steam, the surfaces of the beads are molten or softened leading to cohesion of the beads as a results of an inter-diffusion among the polymer chains of different beads. Uniform cell morphology and the weld lines along with the low content of macro-voids (as a result of good cohesion among the beads) can be observed from the SEM image which ensure the favorable mechanical properties of the molded foam.

The physical properties of the molded SEBS foam were quantified and compared to that of the commercial shoe midsoles made of other TPE, i.e. EVA (Ultralon ${ }^{\circledR}$ EVA260) and TPU (Infinergy ${ }^{\circledR} 32-100$ U10) supplied by the producers (as shown in Table 1). In footwear and sports applications, flexible foam of high elasticity and resiliency is desirable to ensure

Table 1. Physical properties of moldings made from EVA, TPU and SEBS.

\begin{tabular}{|c|c|c|c|}
\hline Properties & EVA & TPU & SEBS \\
\hline Specific gravity & $0.24-0.27$ & 0.265 & 0.252 \\
\hline [Asker C] & $62-72$ & - & 40 \\
\hline Tensile strength & $>2.2$ & 0.7 & 0.7 \\
\hline Elongation at break & $>210$ & 90 & 236 \\
\hline $\begin{array}{l}\text { Compressive strength }[\mathrm{MPa}] \\
\text { at } 10 \% \text { strain } \\
\text { at } 25 \% \text { strain } \\
\text { at } 50 \% \text { strain }\end{array}$ & $\begin{array}{l}>0.375 \\
\quad- \\
\quad-\end{array}$ & $\begin{array}{l}0.055 \\
0.130 \\
0.275\end{array}$ & $\begin{array}{l}0.056 \\
0.116 \\
0.325\end{array}$ \\
\hline Type $\mathrm{C}$ tear & 12 & - & 12 \\
\hline Rebound & - & $>60$ & 72 \\
\hline $\begin{array}{l}\text { Compression set } \\
\left(50 \%, 22 \mathrm{~h}, 23^{\circ} \mathrm{C}\right) \\
24 \mathrm{~h} \text { after stress release }\end{array}$ & $<18$ & $<5$ & 4.5 \\
\hline Water absorption [1 day, vol\%] & - & $<2$ & 1.2 \\
\hline
\end{tabular}
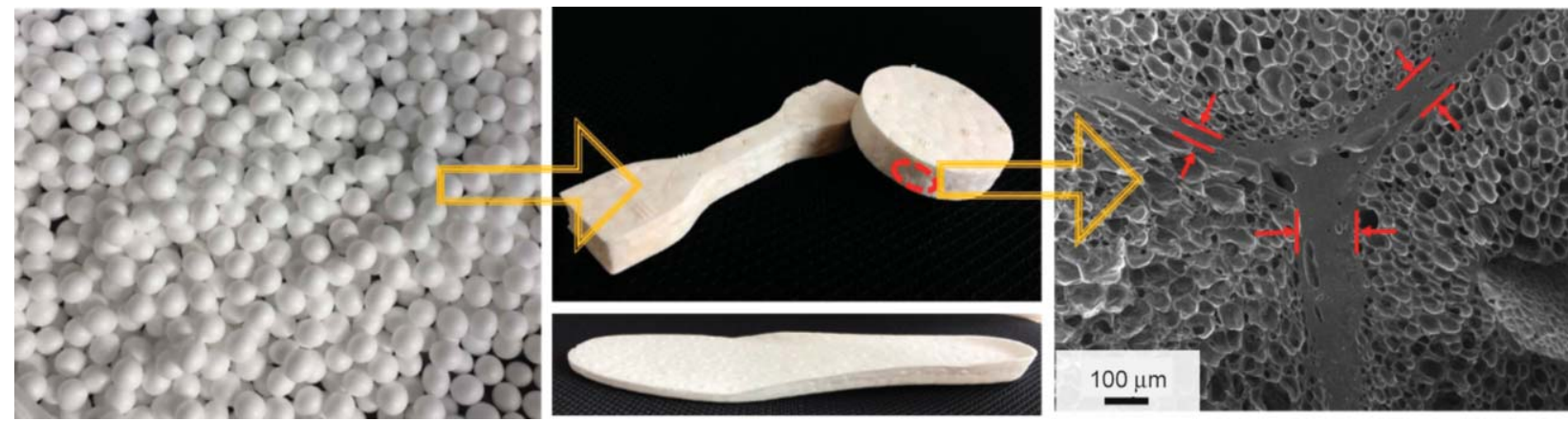

Figure 8. Digital photograph and SEM micrographs of the steam chest molded SEBS bead foam. 
the quick snapback upon unloading the footstrike [57]. Conventional foams (such as EVA, TPU, etc.) exhibit the intermediate elasticity and resiliency with the ball rebound values between 45 and 60\% [58]. The inherent property decided by the molecular chains hinder the improvement of their performances. SEBS owns more flexible main chains and shorter branched chains [59]. Herein, the foam derived from the SEBS beads showed the largest ball rebound value of $72 \%$ while the smallest compression set value of $4.5 \%$ reflecting its higher elasticity and resiliency than that of the TPU or EVA-based foam. Moreover, owing to the lower hardness, tensile strength and compression strength of SEBS-based foams compared to that of the EVA-based foams (at a similar specific gravity), the former is softer than the latter. Although similar tensile and compression properties of SEBS foam are found to that of TPU foam, SEBS foam has an elongation at break recorded to be 1.6 times higher than this recorded for the TPU foam. SEBS being hydrophobic (due to absence of any polar functionalities) shows a lower water absorption of $1.2 \%$ in comparison to the hydrophilic TPU (containing different polar groups) which shows a water absorption more than $2 \%$. According to the aforementioned results and related discussions, it can be said that SEBS is a potential substitution of TPU or EVA for footwear application.

\section{Conclusions}

In this study, eco-friendly, flexible, and lightweight microcellular TPE foam from SEBS has been developed in a facile way through the synergistic combination of irradiation crosslinking, SCF foaming, and steam-chest molding technologies. Being an elastic material, SEBS provides sufficient space to quickly diffuse the impregnated gas during foaming and resulting in the foaming failure. To ensure the successful foaming, SEBS beads were pre-crosslinked (without the use of any chemical agents) under the assistance of irradiation followed by subsequent foaming using the $\mathrm{SC}_{2}$ as blowing agent. As a consequence of irradiation induced crosslinking, the increased modulus (i.e. rigidity) and viscosity hinder the diffusion of $\mathrm{N}_{2}$ and the recovery of molecular chains after expansion to result a successful foaming. The irradiation crosslinking favors well-defined cell structure and high volume expansion ratio of SEBS foam. Herein, the $65 \mathrm{kGy}$-derived I-SEBS-based molded foam not only performs comparable mechanical properties (such as, higher elasticity, higher resilience, etc.) to that of the TPU or EVA based foams, but also a comparable specific gravity (i.e. $0.252 \mathrm{~g} \cdot \mathrm{cm}^{-3}$ ), lower compression strength and lower hardness which make the SEBS as potential alternative of TPU or EVA for footwear applications, were found in SEBS bead foam. Additionally, the hydrophobic nature of SEBS (i.e., only $1.2 \%$ water absorption per day) ensure its longer longevity in an aqueous environment. Taking these advantages into account, the combination technologies of SCF foaming, irradiation, bead foaming make the continuous industrial manufacture of SEBS foam possible for footwear application.

\section{References}

[1] Klempner D., Sendijarevic V., Aseeva R. M.: Handbook of polymeric foams and foam technology. Hanser, Cincinnati (2004).

[2] Szycher M.: Szycher's handbook of polyurethanes. CRC Press, Boca Raton (2012).

[3] Brückner K., Odenwald S., Schwanitz S., Heidenfelder J., Milani T.: Polyurethane-foam midsoles in running shoes - Impact energy and damping. Procedia Engineering, 2, 2789-2793 (2010). https://doi.org/10.1016/j.proeng.2010.04.067

[4] Maiti M., Jasra R. V., Kusum S. K., Chaki T. K.: Microcellular foam from ethylene vinyl acetate/polybutadiene rubber (EVA/BR) based thermoplastic elastomers for footwear applications. Industrial and Engineering Chemistry Research, 51, 10607-10612 (2012). https://doi.org/10.1021/ie300396m

[5] Wang L., Hong Y., Li J. X.: Durability of running shoes with ethylene vinyl acetate or polyurethane midsoles. Journal of Sports Sciences, 30, 1787-1792 (2012). https://doi.org/10.1080/02640414.2012.723819

[6] Shariatmadari M. R., English R., Rothwell G.: Effects of temperature on the material characteristics of midsole and insole footwear foams subject to quasi-static compressive and shear force loading. Materials and Design, 37, 543-559 (2012).

https://doi.org/10.1016/j.matdes.2011.10.045

[7] Wang D., Fujinami S., Liu H., Nakajima K., Nishi T.: Investigation of true surface morphology and nanomechanical properties of poly(styrene- $b$-ethylene-co-butylene- $b$-styrene) using nanomechanical mapping: Effects of composition. Macromolecules, 43, 9049-9055 (2010).

https://doi.org/10.1021/ma100959v

[8] Daniel C., Hamley I. W., Mortensen K.: Effect of planar extension on the structure and mechanical properties of polystyrene-poly(ethylene-co-butylene)-polystyrene triblock copolymers. Polymer, 41, 9239-9247 (2000). https://doi.org/10.1016/S0032-3861(00)00308-6 
[9] Ott H., Abetz V., Altstädt V.: Morphological studies of poly(styrene)-block-poly(ethylene-co-butylene)-blockpoly(methyl methacrylate) in the composition region of the 'knitting pattern' morphology. Macromolecules, 34, 2121-2128 (2001). https://doi.org/10.1021/ma0017079

[10] Wu Z., Wang H., Tian X., Ding X., Xue M., Zhou H., Zheng K.: Mechanical and flame-retardant properties of styrene-ethylene-butylene-styrene/carbon nanotube composites containing bisphenol A bis(diphenyl phosphate). Composites Science and Technology, 82, 8-14 (2013).

https://doi.org/10.1016/j.compscitech.2013.04.003

[11] Vinodh R., Ilakkiya A., Elamathi S., Sangeetha D.: A novel anion exchange membrane from polystyrene (ethylene butylene) polystyrene: Synthesis and characterization. Materials Science and Engineering: B, 167, 4350 (2010).

https://doi.org/10.1016/j.mseb.2010.01.025

[12] Wang X-L., Oh I-K., Lu J., Ju J., Lee S.: Biomimetic electro-active polymer based on sulfonated poly (styrene$b$-ethylene-co-butylene- $b$-styrene). Materials Letters, 61, 5117-5120 (2007). https://doi.org/10.1016/j.matlet.2007.04.004

[13] Cooper A. I.: Porous materials and supercritical fluids. Advanced Materials, 15, 1049-1059 (2003). https://doi.org/10.1002/adma.200300380

[14] Primel A., Férec J., Ausias G., Tirel Y., Veillé J-M., Grohens Y.: Solubility and interfacial tension of thermoplastic polyurethane melt in supercritical carbon dioxide and nitrogen. The Journal of Supercritical Fluids, 122, 52-57 (2017). https://doi.org/10.1016/j.supflu.2016.11.016

[15] Zhang Z. X., Zhang T., Wang D., Zhang X., Xin Z., Prakashan K.: Physicomechanical, friction, and abrasion properties of EVA/PU blend foams foamed by supercritical nitrogen. Polymer Engineering and Science, 58, 673-682 (2018). https://doi.org/10.1002/pen.24598

[16] Di Maio E., Kiran E.: Foaming of polymers with supercritical fluids and perspectives on the current knowledge gaps and challenges. The Journal of Supercritical Fluids, 134, 157-166 (2018). https://doi.org/10.1016/j.supflu.2017.11.013

[17] Yamaguchi M., Suzuki K-I.: Rheological properties and foam processability for blends of linear and crosslinked polyethylenes. Journal of Polymer Science Part B: Polymer Physics, 39, 2159-2167 (2001). https://doi.org/10.1002/polb.1189

[18] Heidari A., Fasihi M.: Cell structure-impact property relationship of polypropylene/thermoplastic elastomer blend foams. Express Polymer Letters, 13, 429-442 (2019).

https://doi.org/10.3144/expresspolymlett.2019.36
[19] Bocz K., Tábi T., Vadas D., Sauceau M., Fages J., Marosi G.: Characterisation of natural fibre reinforced PLA foams prepared by supercritical $\mathrm{CO}_{2}$ assisted extrusion. Express Polymer Letters, 10, 771-779 (2016). https://doi.org/10.3144/expresspolymlett.2016.71

[20] Sharudin R. W. B., Ohshima M.: Preparation of microcellular thermoplastic elastomer foams from polystyrene- $b$-ethylene-butylene- $b$-polystyrene (SEBS) and their blends with polystyrene. Journal of Applied Polymer Science, 128, 2245-2254 (2013).

https://doi.org/10.1002/app.38104

[21] Standau T., Zhao C., Murillo Castellón S., Bonten C., Altstädt V.: Chemical modification and foam processing of polylactide (PLA). Polymers, 11, 306/1-306/39 (2019).

https://doi.org/10.3390/polym11020306

[22] Forest C., Chaumont P., Cassagnau P., Swoboda B., Sonntag P.: Generation of nanocellular foams from ABS terpolymers. European Polymer Journal, 65, 209-220 (2015). https://doi.org/10.1016/j.eurpolymj.2014.11.006

[23] Song J. J., Chang H. H., Naguib H. E.: Design and characterization of biocompatible shape memory polymer (SMP) blend foams with a dynamic porous structure. Polymer, 56, 82-92 (2015).

https://doi.org/10.1016/j.polymer.2014.09.062

[24] Wang G., Zhao J., Mark L. H., Wang G., Yu K., Wang C., Park C. B., Zhao G.: Ultra-tough and super thermalinsulation nanocellular PMMA/TPU. Chemical Engineering Journal, 325, 632-646 (2017).

https://doi.org/10.1016/j.cej.2017.05.116

[25] Spina R.: Technological characterization of PE/EVA blends for foam injection molding. Materials and Design, 84, 64-71 (2015).

https://doi.org/10.1016/j.matdes.2015.06.128

[26] Otsuka T., Taki K., Ohshima M.: Nanocellular foams of PS/PMMA polymer blends. Macromolecular Materials and Engineering, 293, 78-82 (2008). https://doi.org/10.1002/mame.200700257

[27] Hossieny N., Shaayegan V., Ameli A., Saniei M., Park C. B.: Characterization of hard-segment crystalline phase of thermoplastic polyurethane in the presence of butane and glycerol monosterate and its impact on mechanical property and microcellular morphology. Polymer, 112, 208-218 (2017).

https://doi.org/10.1016/j.polymer.2017.02.015

[28] Eaves D.: Handbook of polymer foams. Rapra Technology, Shrewsbury (2004).

[29] Liu C-P., Wang M-K., Xie J-C., Zhang W-X., Tong Q-S.: Mechanochemical degradation of the crosslinked and foamed EVA multicomponent and multiphase waste material for resource application. Polymer degradation and Stability, 98, 1963-1971 (2013). https://doi.org/10.1016/j.polymdegradstab.2013.07.019 
[30] Rodríguez-Pérez M. A.: Crosslinked polyolefin foams: Production, structure, properties, and applications. in 'Crosslinking in materials science' (eds.: Abe A., Dusek K., Kobayashi S.) Springer, Berlin, 184, 97-126 (2005). https://doi.org/10.1007/b136244

[31] Li C., Qiu L., Zhang B., Li D., Liu C-Y.: Robust vacuum-/air-dried graphene aerogels and fast recoverable shape-memory hybrid foams. Advanced Materials, 28, 1510-1516 (2016). https://doi.org/10.1002/adma.201504317

[32] Huang W., Gao X., Xiong J., Xiong L., Xu Y., Fu Y. Electron-beam-induced radiation effects on siloxane foam. Macromolecular Symposia, 297, 225-230 (2010). https://doi.org/10.1002/masy.200900102

[33] Shimazaki Y., Nozu S., Inoue T.: Shock-absorption properties of functionally graded EVA laminates for footwear design. Polymer Testing, 54, 98-103 (2016). https://doi.org/10.1016/j.polymertesting.2016.04.024

[34] Chattopadhyay S., Chaki T. K., Bhowmick A. K.: Development of new thermoplastic elastomers from blends of polyethylene and ethylene-vinyl acetate copolymer by electron-beam technology. Journal of Applied Polymer Science, 79, 1877-1889 (2001).

https://doi.org/10.1002/10974628(20010307)79:10<1877::AID-APP170>3.0.CO;2-B

[35] Ma J., Shao L., Xue C., Deng F., Duan Z.: Compatibilization and properties of ethylene vinyl acetate copolymer (EVA) and thermoplastic polyurethane (TPU) blend based foam. Polymer Bulletin, 71, 2219-2234 (2014).

https://doi.org/10.1007/s00289-014-1183-5

[36] Wu K., Wang J., Lin F., Liu Y., Yang K., Zhou X., Zhang D.: Modification and characterization of the poly(vinyl chloride)/thermoplastic polyurethane foam composite material. Polymer Composites, 35, 17161722 (2014).

https://doi.org/10.1002/pc.22825

[37] Ghazali Z., Johnson A. F., Dahlan K. Z.: Radiation crosslinked thermoplastics natural rubber (TPNR) foams. Radiation Physics and Chemistry, 55, 73-79 (1999). https://doi.org/10.1016/S0969-806X(98)00296-5

[38] Xing Z., Wu G., Huang S., Chen S., Zeng H.: Preparation of microcellular cross-linked polyethylene foams by a radiation and supercritical carbon dioxide approach. The Journal of Supercritical Fluids, 47, 281-289 (2008). https://doi.org/10.1016/j.supflu.2008.08.009

[39] Yang C., Zhe X., Zhang M., Wang M., Wu G.: Radiation effects on the foaming of atactic polypropylene with supercritical carbon dioxide. Radiation Physics and Chemistry, 131, 35-40 (2017).

https://doi.org/10.1016/j.radphyschem.2016.10.018

[40] Yang C-G., Wang M-H., Zhang M-X., Li X-H., Wang H-L., Xing Z., Ye L-F., Wu G-Z.: Supercritical $\mathrm{CO}_{2}$ foaming of radiation cross-linked isotactic polypropylene in the presence of TAIC. Molecules, 21, 1660/11660/11 (2016).

https://doi.org/10.3390/molecules21121660
[41] Kee E.: Novel manufacturing processes for polymer bead foams. PhD Thesis, University of Toronto (2010).

[42] Raps D., Hossieny N., Park C. B., Altstädt V.: Past and present developments in polymer bead foams and bead foaming technology. Polymer, 56, 5-19 (2015). https://doi.org/10.1016/j.polymer.2014.10.078

[43] Zhai W., Kim Y-W., Jung D. W., Park C. B.: Steamchest molding of expanded polypropylene foams. 2 . Mechanism of interbead bonding. Industrial and Engineering Chemistry Research, 50, 5523-5531 (2011). https://doi.org/10.1021/ie101753w

[44] Nofar M., Ameli A., Park C. B.: A novel technology to manufacture biodegradable polylactide bead foam products. Materials and Design, 83, 413-421 (2015). https://doi.org/10.1016/j.matdes.2015.06.052

[45] Guo Y., Hossieny N., Chu R. K., Park C. B., Zhou N.: Critical processing parameters for foamed bead manufacturing in a lab-scale autoclave system. Chemical Engineering Journal, 214, 180-188 (2013). https://doi.org/10.1016/j.cej.2012.10.043

[46] Nofar M., Guo Y., Park C. B.: Double crystal melting peak generation for expanded polypropylene bead foam manufacturing. Industrial and Engineering Chemistry Research, 52, 2297-2303 (2013). https://doi.org/10.1021/ie302625e

[47] Ge C., Ren Q., Wang S., Zheng W., Zhai W., Park C. B.: Steam-chest molding of expanded thermoplastic polyurethane bead foams and their mechanical properties. Chemical Engineering Science, 174, 337-346 (2017). https://doi.org/10.1016/j.ces.2017.09.011

[48] Banerjee R., Sinha Ray S., Ghosh A. K.: Dynamic rheology and foaming behaviour of styrene-ethylenebutylene-styrene/polystyrene blends. Journal of Cellular Plastics, 53, 389-406 (2017).

https://doi.org/10.1177/0021955X16652108

[49] Sharudin R. W. B., Ohshima M.: $\mathrm{CO}_{2}$-induced mechanical reinforcement of polyolefin-based nanocellular foams. Macromolecular Materials and Engineering, 296, 1046-1054 (2011).

https://doi.org/10.1002/mame.201100085

[50] Malmierca M. A., González-Jiménez A., Mora-Barrantes I., Posadas P., Rodríguez A., Ibarra L., Nogales A., Saalwächter K., Valentín J. L.: Characterization of network structure and chain dynamics of elastomeric ionomers by means of ${ }^{1} \mathrm{H}$ low-field NMR. Macromolecules, 47, 5655-5667 (2014). https://doi.org/10.1021/ma501208g

[51] Zhao L., Li J., Li Z., Zhang Y., Liao S., Yu R., Hui D.: Morphology and thermomechanical properties of natural rubber vulcanizates containing octavinyl polyhedral oligomeric silsesquioxane. Composites Part B: Engineering, 139, 40-46 (2018).

https://doi.org/10.1016/j.compositesb.2017.11.052 
[52] Xu H., Zhang Y., Yang J., Ye L., Wu Q., Qu B., Wang Q., Wang Z.: Simultaneous enhancements of toughness and tensile strength for thermoplastic/elastomer blends through interfacial photocrosslinking with UV radiation. Polymer Chemistry, 4, 3028-3038 (2013). https://doi.org/10.1039/C3PY00185G

[53] Luan S., Zhao J., Yang H., Shi H., Jin J., Li X., Liu J., Wang J., Yin J., Stagnaro P.: Surface modification of poly(styrene- $b$-(ethylene-co-butylene)- $b$-styrene) elastomer via UV-induced graft polymerization of $N$-vinyl pyrrolidone. Colloids and Surfaces B: Biointerfaces, 1, 127-134 (2012).

https://doi.org/10.1016/j.colsurfb.2011.12.027

[54] Juárez D., Ferrand S., Fenollar O., Fombuena V., Balart R.: Improvement of thermal inertia of styrene-ethylene/butylene-styrene (SEBS) polymers by addition of microencapsulated phase change materials (PCMs). European Polymer Journal, 47, 153-161 (2011).

https://doi.org/10.1016/j.eurpolymj.2010.11.004
[55] Liu J., Cao D., Zhang L.: Static and dynamic properties of model elastomer with various cross-linking densities: A molecular dynamics study. The Journal of Chemical Physics, 131, 034903/1-034903/10 (2009). https://doi.org/10.1063/1.3179691

[56] Yousefzade O., Hemmati F., Garmabi H., Mahdavi M.: Assisted heterogeneous multinucleation and bubble growth in semicrystalline ethylene-vinyl acetate copolymer/expanded graphite nanocomposite foams: Control of morphology and viscoelastic properties. Express Polymer Letters, 9, 932-944 (2015). https://doi.org/10.3144/expresspolymlett.2015.84

[57] Lippa N. M., Collins P. K., Bonacci J., Piland S. G., Rawlins J. W., Gould T. E.: Mechanical ageing performance of minimalist and traditional footwear foams. Footwear Science, 9, 9-20 (2017). https://doi.org/10.1080/19424280.2016.1228702

[58] Obi B.: Polymeric foams structure-property-performance: A design guide. William Andrew, Norwich (2017).

[59] Drobny J. G.: Handbook of thermoplastic elastomers. Elsevier, Oxford (2014). 